ANNALES

UNIVERSITATIS MARIAE CURIE-SKŁODOWSKA

LUBLIN - POLONIA

VOL. LXXI, 2

SECTIO AA

2016

\title{
Microplastics in the environment: characteristic, identification and potential risk
}

\author{
Aleksandra Bogusz* and Patryk Oleszczuk \\ Department of Environmental Chemistry \\ Maria Curie-Sklodowska University \\ Maria Curie-Sklodowska Sq. 3, 20-031 Lublin \\ "email:aleksandra0989@gmail.com
}

Plastics are widely used in industry as well as in a daily lives. Large amounts of plastics debris are delivered into environment, especially into aqueous ecosystems and transformed into microplastics. The present rewiev work describes microplastics as the marine environment contaminants, their sources and also methods of their identification in the environment. Moreover, the ability of plastics to acculumation of organic and inorganic contaminants and possible harmful effect on the aquatic organisms is also discussed in the presented work.

Keywords: marine environment, microplastics, plastic debris, influence on marine organisms

\section{INTRODUCTION}

Now-a-days, the global production of plastics has exceeded 260 milion tones per year, giving the average annual growth about 9\% [1]. These materials are classified to synthetic organic polymers, produced by polimerisation of monomers which were extracted from oil or gas [2]. Because of their lightweight, strength, durability and low price 
plastics are used in the production of varius materials. The poor rate of recycling of this kind of materials causes the accumulation of plastic in the environment [3]. Plastics can be transported by wind, rivers, tides, storm drains, rainwater, flood events and sewage disposal to the marine environment [4]. Moreover, these plastic debris can persist long time in the sea or ocean water and can be accumulated in the pelagic zones and sedimentary habitats.

Plastics are known as biochemically inert materials because of their large molecule size, having no interaction with the endocrine system. For this reason, the penetration of cells of living organism is prevented. Nonetheless, plastic debris consist of molecules characterized by smaller molecular size and for this reason it is possible to pass easy through the cell membrane. Thus, the endocrine system can be disturbed by the plastic small molecules, because they have the ability to interact chemically with biologically important cells [5-7]. The fragmentation into smaller molecules proceeds by mechanical, biological and photochemical processes $[8,9]$. In the marine ecosystems, different types of plastic debris can be recognized as synthetic 'sandblasting' media [8], virgin pellets [10], synthetic fibers derived from clothes [11] and micro beads derived from cosmetics [12]. International agreements defines microplastics as pieces of plastic smaller than numerous size - ranges, with diameters or thickness of $<10 \mathrm{~mm}[13],<5 \mathrm{~mm}[14,15], 2-6 \mathrm{~mm}$ [16], $<2 \mathrm{~mm}$ [17] and $<1 \mathrm{~mm}$ [18-20]. The inconsistency in size characteristic causes many problems with compering with the literature data. Considering this inconvenience the "mesoplastics" term was suggested to addind to the scientific nomenclature for differing the plastics granulates visible to the human eye and identifying only by microscopy [21].

Among the microplastics two group of materials can be distincted, ie. primary and secondary microplastics. The secondary microplastics are the plastic granules obtain after fragmentation of larger plastic pieces, at the sea as well as on the land [22]. The structural integrity of the material can be disturbed by different processes or their combinations, including physical, biological and chemical interactions which cause the fragmentation [23]. This process can proceed under different conditions, 
such as under high temperature, in the presence of UV radiation. Photodegradation of material occurs as a result ofexposure to sunlight. The bond cleavage is possible by oxidation of the polymer matrix causes by UV radiation [24, 25]. The loss in structural intergrity causes the microplastics more available to fragmentation by abrasion, wave - action and turbulence [26]. During following processes granulates became smaller and finally reach the microscopic size [27, 28]. The literature data point out that fragmentation can continue while the nano-size plastics will be obtain. However, the smallest particles of plastics in marine environment are identified to have $1.6 \mu \mathrm{m}$ diameter and the significant increase of amount of nanoplastics in marine environment is observed [29]. This fact of increasing of amount of small plastics causes growing concern from the marine food web.

The primary microplastics, are produced as a form of microscopic size granules. These materials are most often used as a facial - cleaners and cosmetics [30], and moreover as air - blasting media [31] and drug delivery systems [32]. Traditional natural ingredients typically used in exfoliating hand cleaners and facial scrub production were replaced by microplastic "scrubbers" [12]. In case of microplastic using in air blasting technology the potential toxic effect increased because of contamination of these materials by heavy metals, such as cadmium, chromium and lead [31].

\section{SOURCES OF MICROPLASTICS IN THE MARINE ENVIRONMENT}

Plastics can be delivered directly as well as indirectely to the marine environment [33]. It was noticed that nearly $80 \%$ of plastic debris found in the marine litter have a terrestrial origin [21]. Within these litter primary microplastic can be included, e.g. materials used in cosmetics and air-blasting. Moreover, the important sources of plastics in seawater or ocean are leachates from refuse sites.

It is worth to emphasize that almost half of the global population live in the areas near than 50 miles of the coast, what makes easier to transfer 
microplastic from urban areas to marine evironemnt via wastewater systems, rivers and being transferred by wind [34]. Domestic and also industrial drainage systems are considered to be entering waterways for plastic common used in cosmetics and media of air blasting [2]. Furthermore, large amounts of the plastic debris trapped from wastewater within sewage slugde or oxidation ponds pass through the membrane of filtration systems and are transported out to the marine environment [23]. Extreme weather conditions, e.g hurricanes or flash flooding, can enhance the microplastics transfer from land to water ecosystems [35]. The research performed in Californian waters indicates that the amount of plastic debris with diameter about $<4.75 \mathrm{~mm}$ icreased rapidly from 10 plastic items $/ \mathrm{m}^{3}$ to 60 plastic items $/ \mathrm{m}^{3}$ after a storm [36]. The different study carried out also in Californian waters region shows that concentration of microplastic at the $0.8 \mathrm{~km}$ distance from southern Californian coast has changed from an average $<1$ plastic items $/ \mathrm{m}^{3}$ to 18 plastic items $/ \mathrm{m}^{3}$ after a storm [37].

The direct impact on increasing of amount of plastics debris in marine environment has the exploitation of coastal region, including tourism, commercial fishing, marine - industries as well as marine vessels. Macroplastics and secondary microplastics deliver into water ecosystems posing a risk to living aquatic organisms because of their long - term of degradation. The most common plastic derbis found in the marine enviromonment are fishing accessories [21]. Gear such as nylon netting and plastic monofilament, discarded or lost during the fishing can drift within variable depths of the oceans. It is especially dangerous for marine biota causing the "ghost fishing", what means that aquatic organisms could stick in these plastic debris [33].

\section{ACCULULATION OF POLLUTANTS BY MICROPLASTICS}

Marine platic debris, especially microplastics due to their large ratio of surface area to volume can sorb a number of waterborne contamiants, such as aqueous metal ions [38], endocrine disrupting chemicals [39], hydrophobic organic contaminants (HOCs) and reffered also to persistent 
organic pollutants (POPs) [28]. The low-density microplastics are the most common in the sea - surface microlayer. Moreover, such chemicals as these listed above are also the most abundant in this layer and found at the highest concentration [40]. Stable, lipophilic chemicals like POPs (including polychlorinated biphenyls PCBs, polycyclic aromatic hydrocarbons (PAHs) and organochlorine pesticides (such as DDT, DDE) have the suitable properties to adhere and concentrate on the plastics hydrophobic surface [40]. For phenantrene the adsorption coefficients $\left(K_{d}\right)$ were determined by using equilibrium partinioning modeling for a numerous of plastic polymers in natural sediments and seawater [41]. Phenantrene has higher affinity to sorb on small plastic patricles, especially adhering to polyethylene (PE) characterized by large molecular cavities. When the environmental conditions were relevant phenanthrene prefers adhering to plastics surface than to sediment. Nevertheless, if microplastic loaded with contaminants has a contact with non - polluted sediments, the desorption of phenanthrene from plastic surface to organic mater in the sediment on the basis of concentration gradient would take place.

As a first, PCBs presence was detected on polystyrene spherules structure found in Niantic Bay (USA). However, no supporting information was provided. Later literature data pointed out that polypropylene resin pellets found in Japanese waters may contain several different chemiclas on their surface, such as PCBs, DDE and nonylphenol even at higher concentrations than in sediments [10]. The next experiment presented that virgin resin pellets could sorb pollutants from seawater during six days of exposure. Considering reached adsorption value and constant character of adsorption process, the maximal concentrations were not obtained during studies. It can be explained by the fact that adsorption is a slow process. To detect pollutants adsorbed on the resin pellets surface in Japanese water gas chromatograp with mass spectrometry (GC-MS) was used. In the samples the following substances were found 4,4-DDE and PCBs in the concentration ranges of up to 5600 $\mathrm{ng} / \mathrm{g}$ and 39-1200 $\mathrm{ng} / \mathrm{g}$, respectively [28]. It is worth to point out that concentration of PCBs on polystyrene pellets in surrounding water was detected to be $10^{6}$ higher [10]. Two Portuguese beaches were investigated 
regarding to presence of plastic debris. In the samples, the PAH and PCBs were detected with concentration ranging from $0.2-319.2 \mathrm{ng} / \mathrm{g}$ and $0.02-15.56 \mathrm{ng} / \mathrm{g}$, respectively [42]. The analysis of samples collected from neritic and pelagic stations containing plastic fragments $(<10 \mathrm{~mm})$ indicate the presence of the large spectra of chemicals such as PAHs, PCBs, DDTs and different its metabolites, PBDEs and bisphenol A. All chemicals were adhered to the surface of microplastics at concentration range from 1 to $10000 \mathrm{ng} / \mathrm{g}$ [43]. The structures of the most often observed organic compounds on the microplastics are presented in Fig. 1.

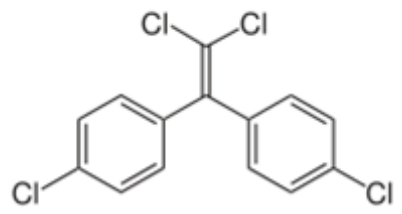

DDE

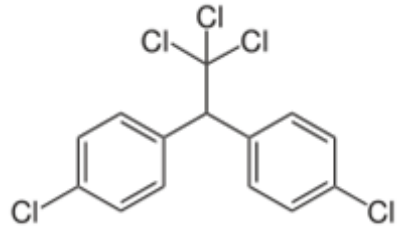

DDT

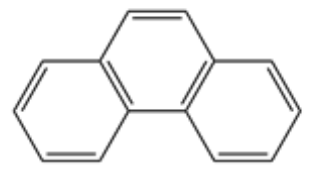

Phenanthrene

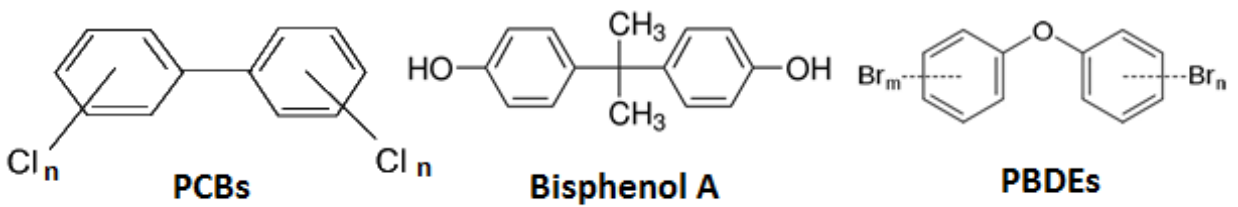

Fig. 1. Chemical structures of main organic contaminants of microplastics.

The group of researchers focused on concentration of PCBs in resin pellets collected from beaches. In individual plastic debris the concentration of chemicals was determined. A large variation in concentration of PCBs among the plastics was observed. Probably, the various factors such as different structures of studied materials, residence time in the marine environment or weathering had an influence on observed differences. The discovered tendency showed that polyethylene pellets sorbed higher concentrations of PCBs than origanted from polypropylene. Next conclusion was related to the fact that fouled and/or yellowing plastic pellets contained higher PCBs concentrations. Yellowing process is a result of oxidation of phenolic additives to products of degradation of quinone-type and, moreover, it indicates the residence time of plastic pellets in the environment. On the basis of above 
mentioned conclusions the monitoring methodology were proposed. The "pellet watch" systems should have been based on yellowing and/ or fouled polyethylene pellets as an indicatiors of coastal contamination by hydrophobic chemicals [44].

This monitoring methodology was expanded to the global scale and called "International Pellet Watch". Local volunteers are collecting plastic resin pellets on the beaches. In the next step, samples are sending to Tokio University of Agriculture and Technology to conduct the analysis of HOCs. During "International Pellet Watch" it was analyzed 27 samples collected by volunteers from 16 countries. The obtained results are presented in Fig. 2.

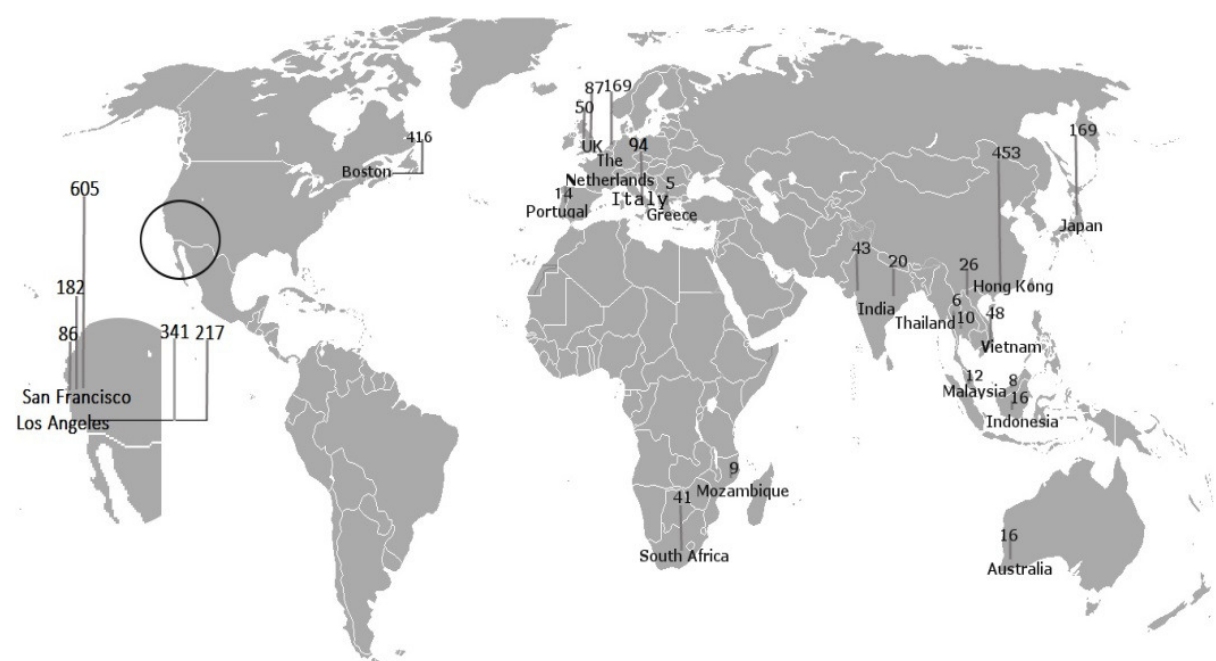

Fig. 2. PCBs concentration in beached plastics resins [ng/g pellet], concentration is a sum of CB nos 66, 101, 149, 118, 105, 153, 138, 128, 187, 180, 170, 206.

The highest concentration of PCBs measured in beached plastic resins was found on the USA coasts, including San Francisco, Los Angeles and Boston. Next, higher chemicals values were also discovered in Japanese and European beaches, such as The Netherlands, United Kingdom and Italy. The much lower PCBs concentrations were measured in samples originating from Austraila, tropical Asia and southern Africa. The obtained results are corresponding with popularity in application of PCBs e.g. in industry. The largest amounts of these chemicals are used in 
USA, Japan and Western Europe what has the confirmation in measured concentration in samples of collected plastic resins. Thus, the minimal usage of PCBs occurs in Austraila, tropical Asia and southern Africa. It is worth to emphasize the fact that more than half of PCBs global production was realized in USA [45]. High PBCs concentration can be still found in seawater, sediments and marine biota in the United States, Japan and Western Europe.

Furthermore, plastics are able to accumulate of metals. The research group distributed unpolluted virgin pre - production plastic pellets in San Diego Bay (USA) at three locations and recovered each of them after 1, 3, 6 , 9 or 12 months. In the obtained samples were analyzed for determination the concetrations of $\mathrm{Al}, \mathrm{Cr}, \mathrm{Mn}, \mathrm{Fe}, \mathrm{Co}, \mathrm{Ni}, \mathrm{Zn}, \mathrm{Cd}$ and $\mathrm{Pb}$ by ICP MS for PET, HDPE, PVC, LDPE and PP materials. The obtained metals concentration ranged from $10^{-1}$ to $10^{5} \mathrm{ng} / \mathrm{g}$ of pellet [53In contrast to organic pollutants, the accumulation of metals on microplastics is not strictly correlated with type of polymer. The mediation by a biofilm was suggested as a possible explanation. It is characteristic for aquatic ecosystems that biofilms have a sorption abilities and accumulate metal ions and other pollutants [46]. High density polyethylene (HDPE) accumulates significantly less concentration of metals, including chromium, nickel, zinc, cadmium and lead than other studied plastics. However, HDPE sorbed greater concentrations of PCBs. In the United States, some heavy metals like $\mathrm{Ni}, \mathrm{Cd}, \mathrm{Zn}, \mathrm{Pb}$ are classified as a priority pollutants. In case of European Union the list is shorter and included only nickel, cadmium and lead. Changes in determinated metal concentration can be caused by e.g. stormwater runoff, recreational boating or shipyard activity [47]. The same conclusion can be proposed for organic and metal pollutants, that longer time of remaining in the marine environment caused the growth in accumulated concentrations of contaminants [48]. In the model laboratory adsorption system the equilibrium state of pollutants acculumating is reached slower, in comparison to the real aquatic environment [49]. The explanation of this effect was given as follows, weathers plastic debris generate oxygen groups (the polarity increased) and foul (roughness, porosity and charge increased), the surface area is growing making the plastics surface reactivity [10, 50-52]. 
Considering above mentioned facts metals accumulation is enhanced [53]. Thus, microplastics perisist for a long time in the marine environment are able to accumulate greater concentration of a contaminants mixture over time [50].

\section{THE INFLUENCE OF MICROPLASTICS ON THE MARINE ENVIRONMENT}

Considering the small size of microplastics and their presence in benthic and pelagic ecosystems the risk of ingestion by aquatic organisms is highly possible [54]. Many experiments performed in the laboratory proved that marine organisms such as invertebrates, zooplankton and echinoderm larvae are able to ingest microplastics [55-57]. As a first Acartia tonsa were used in laboratory conditions to investigate the ingestion experiment. Applied microplastics were characterized by 7-70 $\mu \mathrm{m}$ range size. The microscopy technique was used for indentification of microplastic accumulated by the organisms [58]. The above mentioned lower trophic organisms are known to be susceptible to ingest microplastics and not able to distinguish food from particles of plastics [25]. The study carried out in North Pacific Ocean suggested that white and lightly-coloured microplastics are commonly mistaken with prey by planktonic organisms [59]. Some kind of plastics, e.g. polystyrene and polyethylene, which can be characterized by low density, are buoyant and present near the surface of sea. Because of this fact these microplastics are available for the organisms abundant in euphotic zone, such as larval stages of numerous commercially important species [12].

Moreover, microplastics can be ingested by many marine species, such as crustaceans, seabirds and fish [60]. In the 1960s the plastics particles were detected in the sea birds guts for the first time. At that moment the annual global production of plastics was not higher than 25 million tonnes [61]. Boerger et al. [62] found nearly 35\% of the fish caught in the cental gyre of North Pacific contained microplastics in the guts. The next study performed in the same region showed that 13 of 141 mesopelagic fish had in the stomachs plastics particles, e.g. plastic 
fragments, fibres or films [63]. Different paper informed about nearly 83\% of Nephrops sp. having fragments of plastics bags and monofilament line in the guts [64]. Microplastics fibers discovered in the marine environment have small size, $15 \mu \mathrm{m}$ in length and $1 \mu \mathrm{m}$ in diameter, making them available for ingestion even to the smallest planktonic species [65].

The ingestion of microplastics by small aquatic organisms is considered to be as much harmful as ingestion macroplastics by larger animals [12]. The possible interaction may be correlated with blocking feeding appendages or hinding the food passage through the inestial tract [66]. Moreover, ingestion of microplastics can caused pseudo - satination what lead to reducing food intake [2]. Ryan carried out the experiment with Gallus domesticus for identifing the influence of microplastic ingestion on seabirds health [67]. As the results suggested that ingestion of plastics caused reducing the volume of stomach, feeding stimulus and reducing of meal size [67]. Subsequent harmful effects are correlated with diminished feeding stimulus, lower loevels of steroid hormone, blockage of secrection of gastric enzyme, reproductive failure and delayed ovulation [68].

Microplastics can be considered as a transfer medium of contaminants to organisms. Ingestion of small plastics pieces with pollutants accumulated on the surface by marine biota taking a risk of affecting sorbed chemicals with animals. Thompson performed the experiment to evaluate the probability of desorption pollutants from microplastics during the contact with living tissue of marine biota. As a test organisms Arenicola marina was applied. Four type of chemicals were used as a plastics contaminats, such as phenathrene, PBDE, triclosan and nonylphenols sorbed on PVC. Exposure time for studied organisms with sediments containing $5 \%$ dosage of polluted plastics was established to be 10 days. After this period the concentration of examined chemicals in Arenicola marina tissue was significant higher than in sediments. It was a confirmation that polluted microplastics can be act as vehicle for organic pollutants [22]. Later Teutens study on Arenicola marina tendency of accumulation of phenanthrene lead to conclusion that contamination in plastics after ingestion could be desorbed from surface 
and accumulated in tissue [41]. A cosenquence of reaching the equilibrium state by organisms with surrounding environment is pollutants accumulation in the tissues. A great method for to estimate burden of contaminants in biota is determination of concentration of contaminant in equilibrium state between lipids of animal and surrounding environment [69]. Above mentioned method has been widely used for explanation of inorganic and organic pollutants accumulation in soil-dwelling and sediment organisms [70]. Considering the fact of reaching the equilibrium by organisms, Teuten demonstrated in a continuation of the study that after addition to sediment clean polyethylene the concentration of phenanthrene in Arenicola marina tissue decreased by 13 per cent (compering with previous study without the addition of clean plastics to sandy sediment) [41].

A lot of buoyant plastics are floating in the sea - surface microlayer (SML), where the concentration of contaminants is hightly higher than in the depth [71].

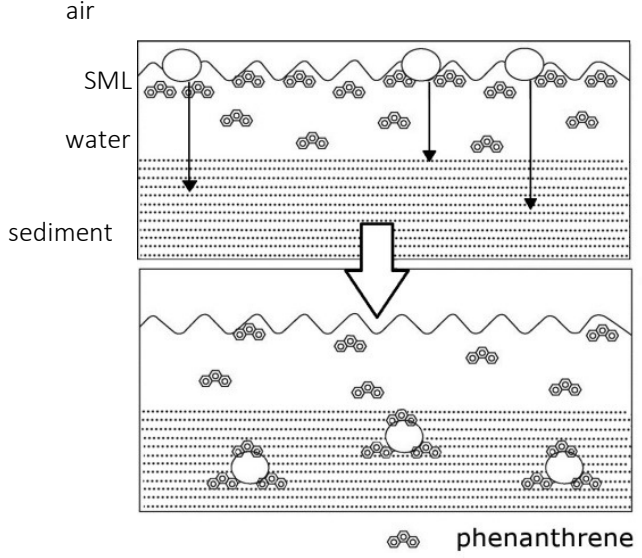

a)

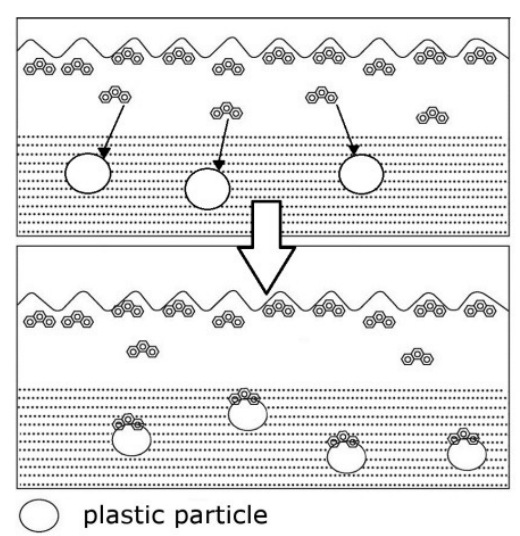

b)

Fig. 3. The mechanisms of transfer of contaminants when: a) clean microplastics are presented in SML, b) clean microplastics are presented in sediment.

Figure 3 presents the mechanism of transfer contaminants (as an example phenanthrene is given) into sediment (Fig. 3.). Two cases should be considered: 
a) accumulation of chemicals by microplastics from SML with transport to sediment (Fig. 3a.),

b) accumulation of chemicals by microplastics from sediment (Fig. 3b.).

Data obtained from calculating suggested that to adsorb high concentration of phenanthrene from SML a small quantity of microplastics was needed. This effect is responsible for transporting of greater concentration of chemicals into sediments what is equal to greater concentration of phenanthrene is tissues of marine biota [41].

\section{INDENTIFICATION OF MICROPLASTICS}

One of the most important steps in microplastics collected from marine environment is their identification and quantification. The greatest problems in this area are correlated with heterogeneity of plastic pieces in color, chemical composition, specific density, shape, size and other characteristics. Thus, selection of suitable method for determination of microplastic is crucial [4].

As a first, sampling strategy should be selected. There were identified three strategies, including bulk, selective and volume - reduced sampling. Bulk samples are dedicated for microplastics piecies which can not be distinguish visually, when sediment particles covered them, their concentration in the sample or size is too low. Selective sampling can be applied when it is possible to identified plastics particles with the naked eye. The last one sampling method is used for samples which bulk volume is reducing during the sampling process [72].

The sampling process consists of four main steps, including the density separation, filtration, sieving and visual sorting. Plastic particles can be characterized by the specific density depending on the manufacturing process and type of polymer. Values of density refer to virgin resins range from $0.8-1.4 \mathrm{~g} / \mathrm{cm}^{3}$, the influence of additivies added during manufacturing process on density was not consider. While sediments and sand have the density of $2.65 \mathrm{~g} / \mathrm{cm}^{3}$. Considering the great difference between densities it is possible to separate light plastics from 
heavy sediments during mixing sediment with saturated solution and next shaking it for a certain period of time. After this period, sediment sample is quickly settle to the bottom causing plastics particles remain in suspension or appear on the solution surface. As a final step of density separation, the supernatant containing microplastics is extracted for next steps of process. During filtration, solution passes through the filter with pore size of 1-2 $\mu \mathrm{m}$ to separate particles of plastics from supernatant [73]. Sieving can be applied for separating microplastics from samples by sieves with different sizes of mesh of $0.038-4.75 \mathrm{~mm}$ allowed to distinguish size category of microplastics. Furthermore, visual sorting is needed to separation microplastics from other materials, including organic debris such as fragments of shells or animal parts, and other items e.g. glass, tar. This step is realized with using naked eye or the aid of a dissecting microscope [74]. To remove other substances and adhered to microplastics surface isolated particles of plastics can be washed, e.g. by using ultrasonic cleaning in a deionized water or a liquid medium [75]. Dried isolated microplastics should be kept in a dark with temperature-controlled conditions for reducing degradation during storage [72].

For identifying microplastics polymer several methods can be applied. The various types of spectroscopy are possible to use, including Fourier transform infrared spectroscopy, infrared spectrophotometer, near-infrared spectrometer. The crystalline structure of the microplastics can be identified by Raman spectroscopy. Moreover, a differential scanning calorimeter was also applied. Specific properties of plastics material can give an information about type of polymer, such as smoke during combustion, specific density or color [72] In Figure 4 the scheme of identification process is shown (Fig. 4).
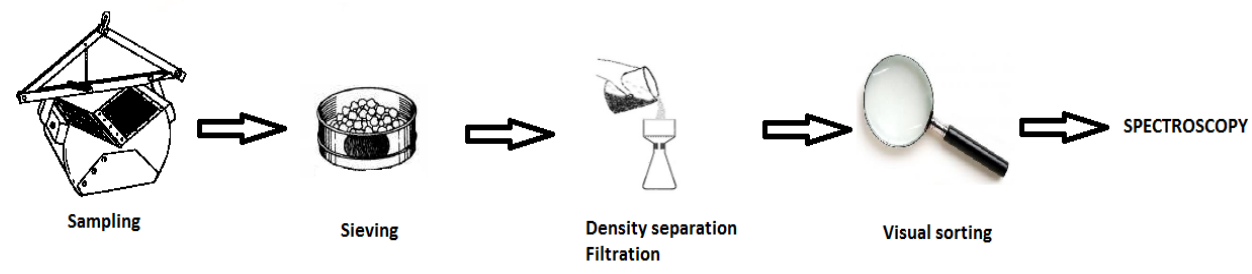

Fig. 4. The scheme of microplastics identification process with sediment sample as an example. 


\section{CONCLUSIONS AND FUTURE REMARKS}

This paper is focused on growing amount of microplastics in the marine environment and their negative impact on aquatic biota. The contamination by plastics particles became a global environmental problem. A massive production of single-use platics is the main cause of this situation. It was proved that plastics finding in the water, sediment or sand have organic and inorganic contaminants accumulated on the surface. The role of microplastics as a vehicle for above mentioned pollutants is evident.

Taking into account the fact that it is slightly possible to removed all microplastics from ocean, experiments in the future should study in details how biotic factors (currents, wave action, UV radiation) and biological agents (e.g. seabirds) influence on the transport, accumulation and breakdown of microplastics. Moreover, an important issue is identifying and reducing or even eliminating the sources of plastics particles in the water ecosystems. To rescue the marine environment from microplastics expansion the knowledge gap in this area should be filled soon.

\section{REFERENCES}

[1] Plastic-Europe, APME, Analysis of Plastics Production, Demand and Recovery in Europe; Association of Plastic Manufacturers: Brussels,1-20 (2006).

[2] J.G.B. Derraik, Mar. Pollut. Bull. 44, 842, (2002).

[3] MCS, Beachwatch 2005- The $13^{\text {th }}$ Annual Beach Litter Survey, Marine Conservation Society: Ross-on-way, UK, Herefordshire, 150 (2006).

[4] P.G. Ryan, C.J. Moore, J.A. van Franeker, C.L. Moloney, Philos. T. R. S. B. 364, 1999, (2009).

[5] A. Sivan, Current Opinion in Biotechnology 22, 422, (2011).

[6] D.K.A. Barnes, F. Galgani, R.C. Thompson, M. Barlaz, Philos. T. R. S. B. 364, 1985, (2009).

[7] M.R. Gregory, Philos. T. R. S. B. 364, 2013, (2009).

[8] A.L. Andrady, Mar. Pollut. Bull. 62, 1596, (2011). 
[9] T.M. Davidson, Mar. Pollut. Bull. 64, 1821, (2012).

[10] Y. Mato, T. Isobe, H. Takada, H. Kanchiro, C. Obtake et al., Environ. Sci. Technol. 35, 318, (2001).

[11] M.A. Browne, P. Crump, S.J. Niven, E. Teuten, A. Tonkin et al., Sci. Tech. Libr. 45, 9175, (2011).

[12] L.S. Fendall, M.A. Sewell, Mar. Pollut. Bull. 58, 1225, (2009).

[13] C. Arthur, J. Baker, H. Bamford, Porceedings of the International research workshop on the Occurrence, effects and fate of micro - plastic marine debris, sept. 9 - 11, NOAA Technical Memorandum NOS OR\&R - 30 (2009).

[14] D.K.A. Barnes, A. Walters, L. Goncalves, Mar. Environ. Res. 70, 250, (2010).

[15] K. Betts, Environ. Sci. Technol. 42, 8995, (2008).

[16] M.J. Doyle, W. Watson, N.M. Bowlin, S.B. Sheavly, Mar. Environ. Res. 71, 41, (2011).

[17] A.L. Andrady, M.A. Neal, Philos. T. R. S. B. 364, 1977, (2009).

[18] [18] P.G. Ryan, C. Moore, J.A. Franeker, C.L. Moloney, Philos. T. R. S. B. 364, 1999 - 2012, (2009).

[19] M.A. Browne, T. Galloway, R. Thompson, Intergated Environ-mental Assessment and Management 3, 559 , (2007).

[20] M. Classens, S.D. Meester, L.V. Landuyt, K.D. Clerck, C.R. Janssen, Mar. Pollut. Bull. 62, 2199, (2011).

[21] M. Costa, J. Ivar do Sul, J. Silva-Cavalcanti, M. Araújo, Â. Spengler, P. Tourinho, Environ. Monit. Assess. 168, 299, (2010).

[22] R.C. Thompson, Y. Olsen, R.P. Mitchell, A. Davis, S.J. Rowland, A.W.G. John, D. McGonigle, A. E. Russell, Science 838 (2004).

[23] M.A. Browne, T. Galloway, R. Thompson, Intergrated Environ-mental Assessment and Management 3, 457, (2007).

[24] D.K.A. Barnes, Nature 416, 808, (2002).

[25] C.J. Moore, Environ. Res. 108, 131, (2008).

[26] D.K.A. Barnes, F. Galgani, R.C. Thompson, M. Barlaz, Philos. T. R. S. B. 364, 1985, (2009).

[27] M. Cole, P. Lindeque, C. Halsband, T.S. Galloway, Mar. Pollut. Bull. 62, 2588, (2011).

[28] L.M. Rios, C. Moore, P.R. Jones, Mar. Pollut. Bull. 54, 1230, (2007). 
[29] F. Galgani, D. Fleet, J.V. Franeker, S. Katsanevakis, T. Maes, J. Mouat, L. Oosterbaan, I. Poitou, G. Hanke, R. Thompson, E. Amato, A. Birkun, C. Janssen, Task group 10 report: marine litter, N. Zampoukas (Ed.), Marine Strategy Framework Directive, JRC, IFREMER \& ICES (2010).

[30] V. Zitko, M. Hanlon, Mar. Pollut.Bull. 22, 41, (1991).

[31] M.R. Gregory, Mar. Pollut. Bull. 32, 867, (1996).

[32] M.M. Patel, B.R. Goyal, S.V. Bhadada, J.S. Bhatt, A.F. Drugs 23, 35, (2009).

[33] R.L. Lozano, J. Mouat, Marine Litter in the North-East Atlantic Region: Assessment and Priorities for Response, KIMO International (2009).

[34] R.C. Thompson, Plastic debris in the marine environment: consequences and solutions, J.C. Krause, H. Nordheim, S. Bräger (Eds.), Marine Nature Conservation in Europe, Federal Agency for Nature Conservation, Stralsund, Germany, 107, (2006).

[35] R. Thompson, C. Moore, A. Andrady, M. Gregory, H. Takada, S. Weisberg, Science, 1117b, (2005).

[36] C.J. Moore, S.L. Moore, S.B. Weisberg, G.L. Lattin, A.F. Zellers, Mar. Pollut. Bull.44, 1035, (2002).

[37] G.L. Lattin, C.J. Moore, A.F. Zellers, S.L. Moore, S.B. Weisberg, Mar. Pollut. Bull. 49, 291, (2004).

[38] K. Betts, Environ. Sci. Technol. 42, 8995, (2008).

[39] K.L. Ng, J.P. Obbard, Mar. Pollut. Bull. 52, 761, (2006).

[40] E.L. Teuten, J.M. Saquing, D.R.U. Knappe, M.A. Barlaz, S. Jonsson, A. BjÃrn, S.J. Rowland, R.C. Thompson, T.S. Galloway, R. Yamashita, D. Ochi, Y. Watanuki, C. Moore, P.H. Viet, T.S. Tana, M. Prudente, R. Boonyatumanond, M.P. Zakaria, K. Akkhavong, Y. Ogata, H. Hirai, S. Iwasa, K. Mizukawa, Y. Hagino, A. Imamura, M. Saha, H. Takada, Philos. T. R. S. B. 364, 2027, (2009).

[41] E.L. Teuten, S.J. Rowland, T.S. Galloway, R.C. Thompson, Environ. Sci. Technol. 41, 7759, (2007).

[42] J.P.G.L. Frias, P. Sobral, A.M. Ferreira, Mar. Pollut. Bull. 60, 1988, (2010). 
[43] H. Hirai, H. Takada, Y. Ogata, R. Yamashita, K. Mizukawa, M. Saha, C. Kwan, C. Moore, H. Gray, D. Laursen, E.R. Zettler, J.W. Farrington, C.M. Reddy, E.E. Peacock, M.W. Ward, Mar. Pollut. Bull. 62, 1683, (2011).

[44] S. Endo, R. Takizawa, K. Okuda, H. Takada, K. Chiba, H. Kanehiro, H. Ogi, R. Yamashita, T. Date, Mar. Pollut. Bull. 50, 1103, (2005).

[45] M.D Erickson, Analytical Chemistry of PCBs. Boca Raton, CA: Lewis Publisher (1997).

[46] A.W. Decho, Cont. Shelf Res. 20, 1257, (2000).

[47] H. Hirai, H. Takada, Y. Ogata, R. Yamashita, K. Mizukawa, Mar. Pollut. Bull. 62, 1683, (2011).

[48] C.M. Rochman, E. Hoh, B.T. Hentschel, S. Kaye, Environ. Sci. Technol. 47, 1646, (2013).

[49] A.C. Fischer, J.J. Kroon, T. G. Verburg, T. Teunissen, H.T. Wolterbeek, Mar. Chem. 107, 533, (2007).

[50] K.N. Fotopoulou, H.K. Karapanagioti, Mar. Environ. Res. 81, 70, (2012).

[51] T. Artham, M. Sudhakar, R. Venkatesan, C. Madhavan Nair, K. V. G. K. Murty, Int. Biodeter. Biodegr. 63, 884, (2009).

[52] L.A. Holmes, A. Turner, R.C. Thompson, Environ. Pollut. 160, 42, (2012).

[53] C. Tien, C.S. Chen, Arch. Environ. Con. Tox. 64, 605, (2013).

[54] R. Thompson, C. Moore, F.S. vom Saal, S.H. Swan, Philos. T. R. S. B. 364, 2153, (2009a).

[55] T.F. Bolton, J.N. Havenhand, J. Plankton Res. 20, 2153, (1998).

[56] M. Brillant, B. MacDonald, Mar. Biol. 141, 457, (2002).

[57] M.W. Hart, Biol. Bull. 180, 12, (1991).

[58] D.S. Wilson, Ecology 54, 909, (1973).

[59] D.G. Shaw, R.H. Day, Mar. Pollut. Bull. 28, 39, (1994).

[60] L.K. Blight, A.E. Burger, Mar. Pollut. Bull. 34, 323, (1997).

[61] R. Thompson, S.H. Swan, C. Moore, F.S. vom Saal, Philos. T. R. S. B. 364, 1973, (2009b).

[62] C.M. Boerger, G.L. Lattin, S.L. Moore, C. Moore, Mar. Pollut. Bull. 60, 2275, (2010).

[63] P. Davison, R.G. Asch, Mar. Ecol. - Progr. Ser. 432, 173, (2011).

[64] F. Murray, P.R. Cowie, Mar. Pollut. Bull. 62, 1207, (2011). 
[65] J.P.G.L. Frias, P. Sobral, A.M. Ferreira, Mar. Pollut. Bull. 60, 1988, (2010).

[66] P.S. Tourinho, J.A. Ivar do Sul, G. Fillmann, Mar. Pollut. Bull. 60, 396, (2010).

[67] P.G. Ryan, Mar. Pollut. Bull. 19, 125, (1988).

[68] M.Y. Azzarello, E.S. Van - Vleet, Mar. Ecol. - Progr. Ser. 37, 295, (1987).

[69] D.M. Di Toro, C.S. Zarba, D.J. Hansen, W.J. Berry, R.C. Swartz, C.E. Cowan, S.P. Pavlou, H.E. Allen, N.A. Thomas, P.R. Paquin, Environ. Toxicol. Chem. 10, 1541, (1991).

[70] European Chemicals Burneau, Technical guide document on risk assessment, Institute for Health and Consumer Protection (2003).

[71] O. Wurl, J.P. Obbard, Mar. Pollut. Bull. 48, 1016, (2004).

[72] V. Hidalgo-Ruz, L. Gutow, R.C. Thompson, M. Thiel, Environ. Sci. Technol. 46, 3060, (2012).

[73] F. Noren, Small plastics particles in Coastal Swedish waters, KIMO report (2007).

[74] M.J. Doyle, W. Watson, N.M. Bowlin, S.B. Sheavly, Mar. Environ. Res. 71, 41, (2011).

[75] D.A. Cooper, P.L. Corcoran, Mar. Pollut. Bull. 60, 650, (2010). 